\title{
African biomass burning and dust dust are equally important sources of phosphorus deposition to the Amazon
}

\author{
AnNe BARKLEY'; Joseph M. ProsPerO'; NATAlie \\ MAHOWALD ${ }^{3}$; DOUGLAS S. HAMILTON ${ }^{4}$; KIMBERLy J. \\ POPENDORF ${ }^{s}$; ALI POURMAND ${ }^{*}$; ALEXANDRE GATINEAU ${ }^{*}$; \\ KATHY PANECHOU ${ }^{*}$; PATRICIA BLACKWELDER; \\ CASSANDRA J. GASTON \\ 1University of Miami; abarkley@rsmas.miami.edu \\ 2 University of Miami; jprospero@rsmas.miami.edu \\ ${ }^{3}$ Cornell University; mahowald@cornell.edu \\ ${ }^{4}$ Cornell University; dsh224@cornell.edu \\ 5University of Miami; kpopendorf@rsmas.miami.edu \\ 6University of Miami; apourmand@rsmas.miami.edu \\ ${ }^{7}$ ATMO Guyane, Remire-Montjoly, Guyane (French \\ Guiana), France; alexandre.gatineau@gmail.com \\ ${ }^{8}$ ATMO Guyane, Remire-Montjoly, Guyane (French \\ Guiana), France; k.panechou@atmo-guyane.org \\ ${ }^{9}$ University of Miami; pblackwelder@rsmas.miami.edu \\ ${ }^{*}$ correspondence: cgaston@rsmas.miami.edu
}

The deposition of phosphorus ( $\mathrm{P}$ ) from long-range transported African dust is believed to play an important role in bolstering primary productivity in the Amazon Basin. However, there are few measurements of African dust in South America that can robustly test this hypothesis and even fewer measurements of soluble $\mathrm{P}$, which is readily available for stimulating primary production. To test this hypothesis, we measured total and soluble $\mathrm{P}$ in long-range transported aerosols collected in Cayenne, French Guiana, a coastal site located at the northeastern edge of the Amazon that receives transported African dust annually. Our measurements confirm that in boreal Spring when African dust transport is greatest, dust supplies the majority of P, of which $5 \%$ is soluble. Using MERRA-2 to estimate $\mathrm{P}$ deposition from African dust to the Amazon, we found $0.011 \mathrm{Tg} \mathrm{P} \mathrm{a}^{-1}$ deposited, which is within in the range of previously reported remote sensing studies. In boreal Fall, when dust transport is at an annual minimum, we measured unexpectedly high concentrations of $\mathrm{P}$ that was more soluble ( $15 \%$ soluble), which we show is associated with the transport of biomass burning from southern Africa. Integrating our results into a chemical transport model, we show that African biomass burning supplies up to half of the $\mathrm{P}$ deposited annually to the Amazon from transported African aerosol. This recently published study is the first observational study that links P-rich biomass burning aerosols from Africa to enhanced $\mathrm{P}$ deposition in the Amazon. 